\title{
Structure and stability of two polymorphs of creatine and its monohydrate
}

Article

Accepted Version

Arlin, J.-B., Bhardwaj, R. M., Johnston, A., Miller, G. J., Bardin, J., MacDougall, F., Fernandes, P., Shankland, K., David, W. I. F. and Florence, A. J. (2014) Structure and stability of two polymorphs of creatine and its monohydrate. Crystengcomm, 16 (35). pp. 8197-8204. ISSN 1466-8033 doi: https://doi.org/10.1039/c4ce00508b Available at https://centaur.reading.ac.uk/39201/

It is advisable to refer to the publisher's version if you intend to cite from the work. See Guidance on citing.

To link to this article DOI: http://dx.doi.org/10.1039/c4ce00508b

Publisher: Royal Society of Chemistry

All outputs in CentAUR are protected by Intellectual Property Rights law, including copyright law. Copyright and IPR is retained by the creators or other copyright holders. Terms and conditions for use of this material are defined in the End User Agreement.

www.reading.ac.uk/centaur 
Central Archive at the University of Reading

Reading's research outputs online 


\title{
Structure and stability of two polymorphs of creatine and its monohydrate $\dagger$
}

\author{
Jean-Baptiste Arlin, ${ }^{a}$ Rajni M. Bhardwaj, ${ }^{b}$ Andrea Johnston, ${ }^{b}$ Gary J. Miller, ${ }^{b}$ \\ Julie Bardin,b Fiona MacDougall, c Philippe Fernandes, ${ }^{d}$ Kenneth Shankland, ${ }^{e}$ \\ William I. F. Davidf and Alastair J. Florence ${ }^{* b}$
}

\section{Introduction}

\begin{abstract}
An experimental search for crystalline forms of creatine including a variable temperature X-ray powder diffraction study has produced three polymorphs and a formic acid solvate. The crystal structures of creatine forms I and II were determined from X-ray powder diffraction data plus the creatine formic acid $(1: 1)$ solvate structure was obtained by single crystal X-ray diffraction methods. Evidence of a third poly- morphic form of creatine obtained by rapid desolvation of creatine monohydrate is also presented. The results highlight the role of automated parallel crystallisation, slurry experiments and VT-XRPD as power- ful techniques for effective physical form screening. They also highlight the importance of various com- plementary analytical techniques in structural characterisation and in achieving better understanding of the relationship between various solid-state forms. The structural relationships between various solid- state forms of creatine using the XPac method provided a rationale for the different relative stabilities of forms I and II of creatine with respect to the monohydrate form.
\end{abstract}

Creatine (CTN; Scheme 1) is commercially available as a nutritional supplement, mainly in the form of CTN monohydrate. CTN is involved in the metabolic pathway for ATP formation in the muscle under anaerobic conditions. ${ }^{1}$ CTN supplements can increase muscle performance during strenuous exercise by maintaining the high turnover rates of ATP. ${ }^{2,3}$ Worldwide CTN sales were estimated at over 400 million dollars in 2009.

The structure of CTN monohydrate has been studied previously using X-ray and neutron single crystal diffraction ${ }^{4}-6$ and has been reported to desolvate upon heating to produce an anhydrous crystalline form, although no structure was reported.7,8 Upon continued heating to between 503-533 K CTN undergoes a condensation reaction via an intramolecular

\footnotetext{
a Institut Charles Sadron (UPR22-CNRS), 23 rue du Loess, BP 84047, 67034 Strassbourg, Cedex, France

${ }^{\mathrm{b}}$ Strathclyde Institute of Pharmacy and Biomedical Sciences, University of Strathclyde, 161 Cathedral Street, Glasgow G4 0RE, UK.

E-mail: alastair.florence@strath.ac.uk

${ }^{\mathrm{c}}$ Drug Delivery International, 84 Castle Street, Glasgow G4 0SF, UK

d SAFC Pharmorphix, 250 Science Park, Milton Road, Cambridge, CB4 0WE, UK

${ }^{\mathrm{e}}$ School of Pharmacy, University of Reading, Reading, UK

${ }^{\mathrm{f}}$ ISIS Facility, Rutherford Appleton Laboratory, Chilton, Didcot, Oxon, UK OX11 0QX

$\dagger$ Electronic supplementary information (ESI) available: Crystallisation results, IR spectra, geometry optimizations using CASTEP, Pawley type refinement, STA data, XRPD data of relative stability experiments under ambient conditions and competitive slurry experiments. CCDC 990914-990916. For ESI and crystallographic data in CIF or other electronic format see DOI: $10.1039 / \mathrm{c} 4 \mathrm{ce} 00508 \mathrm{~b}$
}

cyclisation to form creatinine. ${ }^{8}$ The crystal structure of an anhydrous crystalline form has been reported very recently ${ }^{9}$ using a combined approach of crystal structure prediction (CSP) and X-ray powder diffraction (XRPD) which matches with form II reported in this study.

Different physical forms of molecular solids can display marked differences in their key physicochemical properties including melting point, solubility, dissolution and stability. Oral bioavailability and stability in the final dosage form are particularly two important properties for a marketed com- pound available for human consumption. Therefore, in order to explore the extent of physical form diversity and relationship amongst various physical forms of this important nutraceutical compound, an experimental screen was implemented using crystallisation from solution, slurrying, in situ desolvation and thermal approaches. ${ }^{10}$ Here we report the crystal structures of
Scheme 1 CTN molecule shown in zwitterionic form as found in the crystal structure of CTN monohydrate. 
two polymorphs forms I and II and a $1: 1$ formic acid solvate of CTN. These crystal structures are further analysed in terms of crystal packing features and are compared to the known crystal structure of CTN monohydrate using the XPac method ${ }^{11}$ to identify the key intermolecular packing motifs that under- pin the physical form diversity of various forms of this com- pound. Also the relationships between crystal structures of the polymorphs and monohydrate and their interconversion ${ }^{12}$ is investigated. Evidence for a third polymorph (form III) of CTN prepared by rapid in situ desolvation is also presented. Due to limited availability of form III samples, only XRPD data and thermal analyses are presented.

\section{Experimental section}

\section{Materials}

Samples of anhydrous CTN and CTN monohydrate were purchased from Sigma and used without further purification. The sample of anhydrous CTN as received was identified as a mixture of CTN monohydrate and CTN II by XRPD.

\section{Methods}

Automated parallel crystallisation

67 solvents covering a wide range of physicochemical properties were used for solution crystallisations of creatine (see ESI, $\uparrow$ Table S1) using an automated parallel crystallisation platform i.e. Chemspeed Accelerator SLT100.13 These crystallisations were carried out in duplicate. Solutions were prepared by adding excess solid in each solvent to ensure that solutions were satu- rated at the appropriate temperature prior to being filtered automatically into a clean crystallisation vessel. Crystallisation was induced by controlled cooling in filtered solutions.

Due to poor solubility of CTN in majority of the tested solvents, slurry experiments were conducted for 51 solvents (see ESI, $\uparrow$ Table S2). Following recrystallisation, suspended samples were reclaimed by filtration and were analysed to confirm its identity using multisample foil transmission XRPD.

\section{Manual slurry experiment}

Approximately $100 \mathrm{mg}$ of anhydrous CTN was placed in a vial and $5 \mathrm{ml}$ of solvent was added. The mixture was left under stirring and suspended samples were analysed regularly using XRPD.

\section{Relative stabilities}

The relative stabilities of CTN I and II was assessed using competitive slurry experiments. ${ }^{14,15}$ A mixture of $51.2 \%$ of CTN I and $48.8 \%$ CTN II was left to slurry in two different solvents (butyl acetate and isoamyl alcohol). The evolution of the mix- ture composition was analysed by ratioing the heights of a selected XRPD peak characteristic of each form. When the ratio became 0 or $\infty$, the remaining phase was assessed as the most stable. Physical stabilities of CTN I and II were assessed by analysing the composition of the samples left under ambi- ent conditions (open bench) over a period of 3 months.

Dynamic vapour sorption analysis

Dynamic vapour sorption (DVS) experiments were conducted on DVS instrument from Surface Measurement Systems. Sam- ples were first exposed to $0 \%$ relative humidity $(\mathrm{RH})$ followed by two hydration/dehydration cycles with humidity values varying from $0 \%, 10 \%, 20 \%, 30 \%, 40 \%, 50 \%, 60 \%, 70 \%, 80 \%, 90 \%$ and $95 \%$. The change of RH was controlled by the variation in the sample mass and it was changed when $\mathrm{dm} / \mathrm{dt}$ was smaller than $0.001 \mathrm{mg}$ $\min ^{-1}$.

X-ray powder diffraction

For crystalline form identification, a small quantity (10-50 mg) of sample was analysed using transmission foil XRPD data collected on a Bruker AXS D8 Advance transmission diffractometer equipped with $\theta / \theta$ geometry, primary monochromated radiation $\left(\mathrm{Cu} \mathrm{K} \alpha_{1} \lambda=1.54056 \AA\right)$, a Braun $1 D$ position sensitive detector (PSD) or a Vantec PSD and an automated multiposition x-y sample stage. Samples were mounted on a 28 position sample plate supported on a polyimide (Kapton, $7.5 \mu \mathrm{m}$ thickness) film. Data were collected from each sample in the range $4-35^{\circ} 2 \theta$ with $0.015^{\circ} 2 \theta$ step size and $1 \mathrm{~s} \mathrm{step}^{-1}$ count time (data collection time per sample ca. 40 minutes). ${ }^{16}$ Samples were oscillated $\pm 0.5 \mathrm{~mm}$ in the $\mathrm{x}-\mathrm{y}$ plane at a speed of $0.3 \mathrm{~mm} \mathrm{~s}^{-1}$ throughout data collection to maximise particle sampling and minimise preferred orientation effects.

For structure determination from X-ray powder diffraction data (SDPD) purposes, samples were loaded in a rotating $0.7 \mathrm{~mm}$ borosilicate glass capillary and mounted on a Bruker AXS D8 Xray powder diffractometer equipped with primary monochromator $\left(\mathrm{Cu} \mathrm{K} \alpha_{1}, \lambda=1.54056 \AA\right)$ and Lynxeye PSD. Data were collected at room temperature in the range $2-70^{\circ} 2 \theta$ with a $0.015^{\circ} 2 \theta$ step size, using a variable count time scheme ${ }^{17,18}$ to improve the accuracy of the intensities at high angle. The diffraction pattern was indexed using the first twenty peaks with DICVOL0 $4^{19}$ as implemented in the DASH structure solution package. Space group determination was carried out using a statistical assessment of systematic absences. A Pawley type refinement ${ }^{20}$ was used to extract the intensities and their correlations. Simulated annealing (SA), as implemented in DASH version $3.1^{21}$ was used to solve the crystal structure from the powder pattern in direct space. The starting molecular geometry was obtained from the neutron single-crystal structure determination of CTN monohydrate [CSD refcode $=$ CREATH05] in which CTN exists as a zwitterion. The zwitterionic state of form I, II and III of CTN was confirmed by ATR FTIR data (see

ESI, $\dagger$ Fig. S1, Table S3). Plane-wave density functional theory calculations using the CASTEP ${ }^{22}$ program were conducted on CTN I, II and CTN monohydrate [CSD refcode = CREATH05] to check the accuracy of the zwitterion configuration (see ESI, $\dagger$ Fig. S2). ${ }^{23,24}$ For both structures, the best DASH solutions returned a $\chi^{2}$ ratio $\left(\chi^{2} \mathrm{SA} / \chi^{2}\right.$ Pawley $)<5$ indicative of an excellent fit to the data. A restrained Rietveld refinement ${ }^{25}$ of the 
global minimum solution obtained from SA was carried out in TOPAS Academic version 4.1. ${ }^{26}$ For CTN I, the final refinement included a total of 97 parameters ( 29 profile, 3 cell, 1 scale, 1 overall isotropic temperature factor, 9 preferred orientation, 54 coordinates), yielding a final $\mathrm{R}_{\mathrm{wp}}=4.1$. For CTN II, the final refinement included a total of 112 parameters (44 profile, 4 cell, 1 scale, 1 overall isotropic temperature factor, 8 preferred orientation, 54 coordinates), yielding a final $\mathrm{R}_{\mathrm{wp}}=4.0$. The resulting structures of form I and II were further scrutinised by allowing all fractional coordinates to refine freely ( $\mathrm{R}_{\mathrm{wp}}=3.0$ and 2.9 for CTN I and II respectively). As expected, the improved $R_{\mathrm{wp}}$ came at the expense of some chemical sense, but otherwise, the geometry of the independent molecules was well preserved, confirming the correctness of the restrained refined crystal structure. ${ }^{27}$

Single crystal X-ray diffraction

$\mathrm{X}$-ray data were collected at $123 \mathrm{~K}$ with graphite monochromatic Mo K $\alpha_{1}$ radiation (wavelength $\mathrm{MoK} \alpha_{1}, \lambda=0.71073 \AA$ ) on a BRUKER APEX II diffractometer equipped with a CCD detector and an Oxford Cryostream variable temperature device. Data reduction and cell refinement were performed using BRUKER SMART and SAINT programs. ${ }^{28}$ Multi-scan absorption correction were applied with the program SADABS. ${ }^{28}$ The struc- ture was solved by direct methods using SHELXS-97 (ref. 29) and refined against $F^{2}$ using SHELXL-97 (ref. 29) within WinGX. ${ }^{30}$ All nonhydrogen atoms were refined anisotropically.

XPac analysis

$\mathrm{XPac}^{11}$ was used to analyse the crystal packing of all physical forms of CTN. Due to the similar conformations of the CTN molecules in each structure, all nine non-hydrogen atoms (Scheme 1) were selected to provide a common ordered set of points (COSPs). The COSPs are the basis of the XPac method and describe the geometry of the common CTN component in each structure. The standard cut-off parameters were used to identify similarities in the angular relationships between CTN molecules in the structures.

\section{Result and discussion}

Preparation of physical forms

Physical form screening of CTN resulted in three polymorphs, one monohydrate and one formic acid solvate (1/1). Methods of preparation for various physical forms are summarised in Table 1.

Fig. 1 shows an overlay of a diagnostic region $\left(12-20^{\circ} 2 \theta\right)$ of the experimental XRPD patterns of the anhydrous forms of CTN, CTN monohydrate and creatinine. All three anhydrous forms of CTN were confirmed to be CTN by IR spectroscopy. CTN formic acid solvate could only be obtained as a mixture with CTN monohydrate although a single crystal of CTN formic acid solvate was extracted from the mixture and used to solve the structure. XRPD data for the mixed phase sample are given in the ESI† (Fig. S3).
Table 1 Summary of the crystallisation methods used to produce physical forms of CTN

\begin{tabular}{|c|c|}
\hline CTN form & Method of preparation \\
\hline Form I & $\begin{array}{l}\text { By slurrying CTNa in isoamyl alcohol } \\
\text { for } 7 \text { days }\end{array}$ \\
\hline Form II & $\begin{array}{l}\text { a) By slurrying CTNa in butyl acetate } \\
\text { for } 14 \text { days } \\
\text { b) By dehydration of CTN monohydrate } \\
\text { in an oven at } 383 \mathrm{~K} \text { for } 2 \text { hours }\end{array}$ \\
\hline Form III & $\begin{array}{l}\text { Rapid dehydration of creatine } \\
\text { monohydrate at } 453 \mathrm{~K}^{\mathrm{b}}\end{array}$ \\
\hline $\begin{array}{l}\text { CTN formic acid solvate } \\
(1: 1)\end{array}$ & $\begin{array}{l}\text { Solution crystallisation of } \mathrm{CTN}^{\mathrm{a}} \text { in } \\
\text { formic acid }\end{array}$ \\
\hline CTN monohydrate & Solution crystallisation of CTN ${ }^{\mathrm{a}}$ in water \\
\hline \multicolumn{2}{|c|}{$\begin{array}{l}\text { CTN purchased from Sigma was used. b Form III was observed } \\
\text { from desolvation of a sample of CTN monohydrate loaded in a capillary and } \\
\text { transferred directly to } 453 \mathrm{~K} \text {. On cooling the same sample within capillary to } \\
\text { room temperature, form III did not transform back to CTN monohydrate. } \\
\text { Although in presence of water, it converted back to CTN monohydrate } \\
\text { immediately. }{ }^{\text {c }} \text { CTN formic acid solvate was not obtained as a pure phase, } \\
\text { therefore only its crystal structure is discussed here. }\end{array}$} \\
\hline
\end{tabular}

The crystal structures of forms I and II were solved using the SDPD approach. Fig. 2 and 3 show the final fits to the experimental data of the Rietveld-refined structures of CTN I and II. XRPD pattern of CTN III could not be indexed and only characteristic powder pattern is presented (see ESI, $\uparrow$ Fig. S4). Crystallographic data for CTN I, II and the CTN formic acid (1/1) solvate are summarised in Table 2. Thermal analyses of CTN I, II, III and CTN formic acid solvate are shown in Fig. S5 and S6 in the ESI. $\dagger$

Relative stability

A polycrystalline sample of CTN II stored in an open vial at room temperature converted to CTN monohydrate within approximately 3 months (see ESI, $\uparrow$ Fig. S7). In contrast, a sample of CTN I was unchanged after a year (see ESI, $\dagger$ Fig. S8), confirming its higher stability over CTN II.

Competitive slurry experiments

A $1: 1$ mixture of CTN I and II was suspended in isoamyl alcohol or butyl acetate at room temperature showed com- plete conversion to CTN I, confirming it is the more stable form (see ESI, $\uparrow$ Fig. S9 and S10).

Anhydrate $\leftrightarrow$ monohydrate phase transformation-moisture sorption/desorption experiments

A more detailed investigation of the transformation between CTN I and II and the monohydrate was carried out using DVS. Samples of both polymorphs were exposed to relative humidities between 0 to $90 \% \mathrm{RH}$ at $298 \mathrm{~K}$. The sorptiondesorption isotherms of CTN II show a typical hysteresis cycle where at $\mathrm{RH}>30 \%$ it transforms to CTN monohydrate and at low RH $(<20 \%)$, the water of the monohydrate is released to give form II CTN which was confirmed using XRPD (Fig. 4). The measured mass loss corresponds to $14 \%$ which is equivalent to one mole of water. 


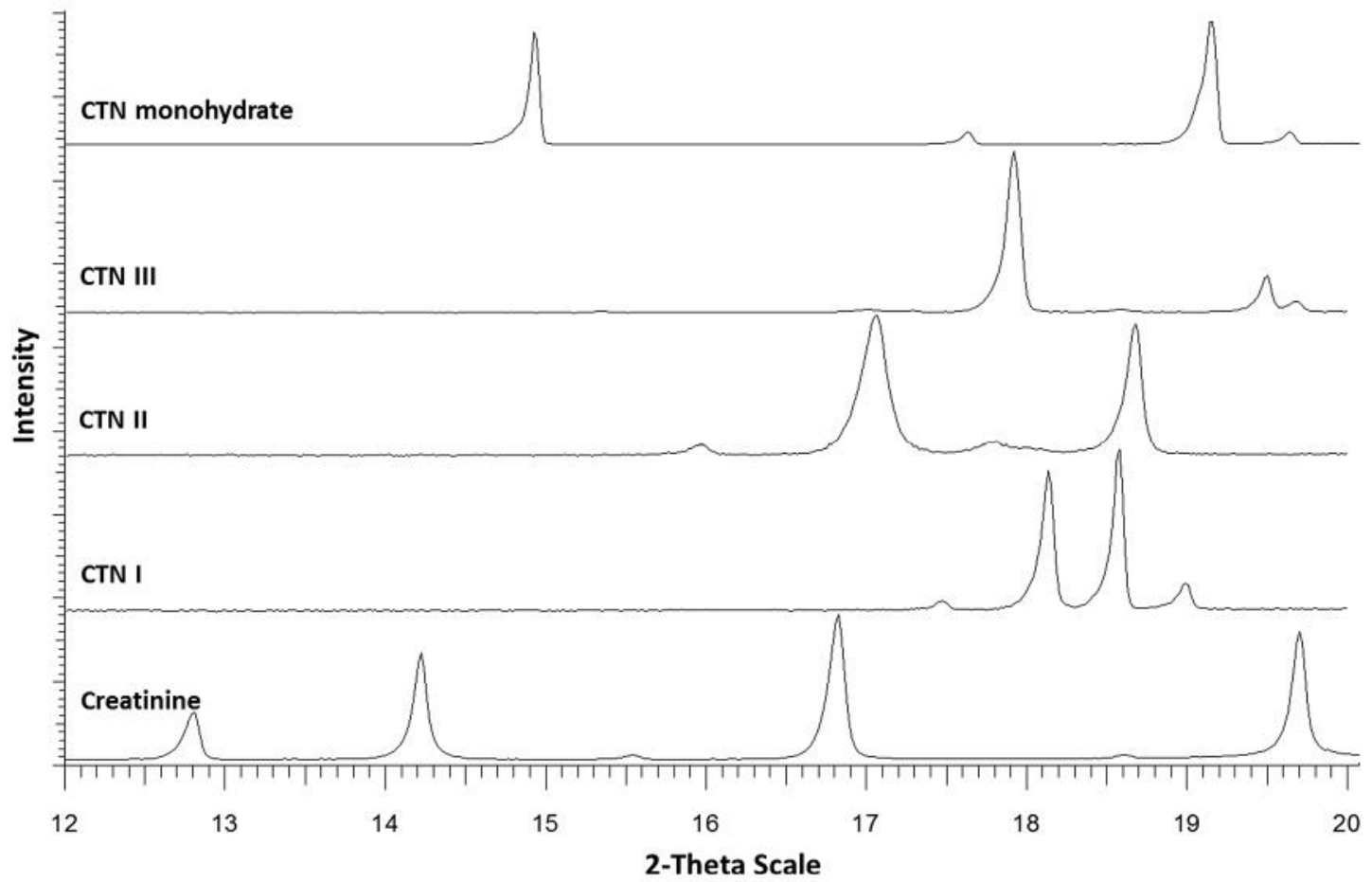

Fig. 1 Diagnostic region in the XRPD patterns of creatinine, CTN forms I, II and III and CTN monohydrate.
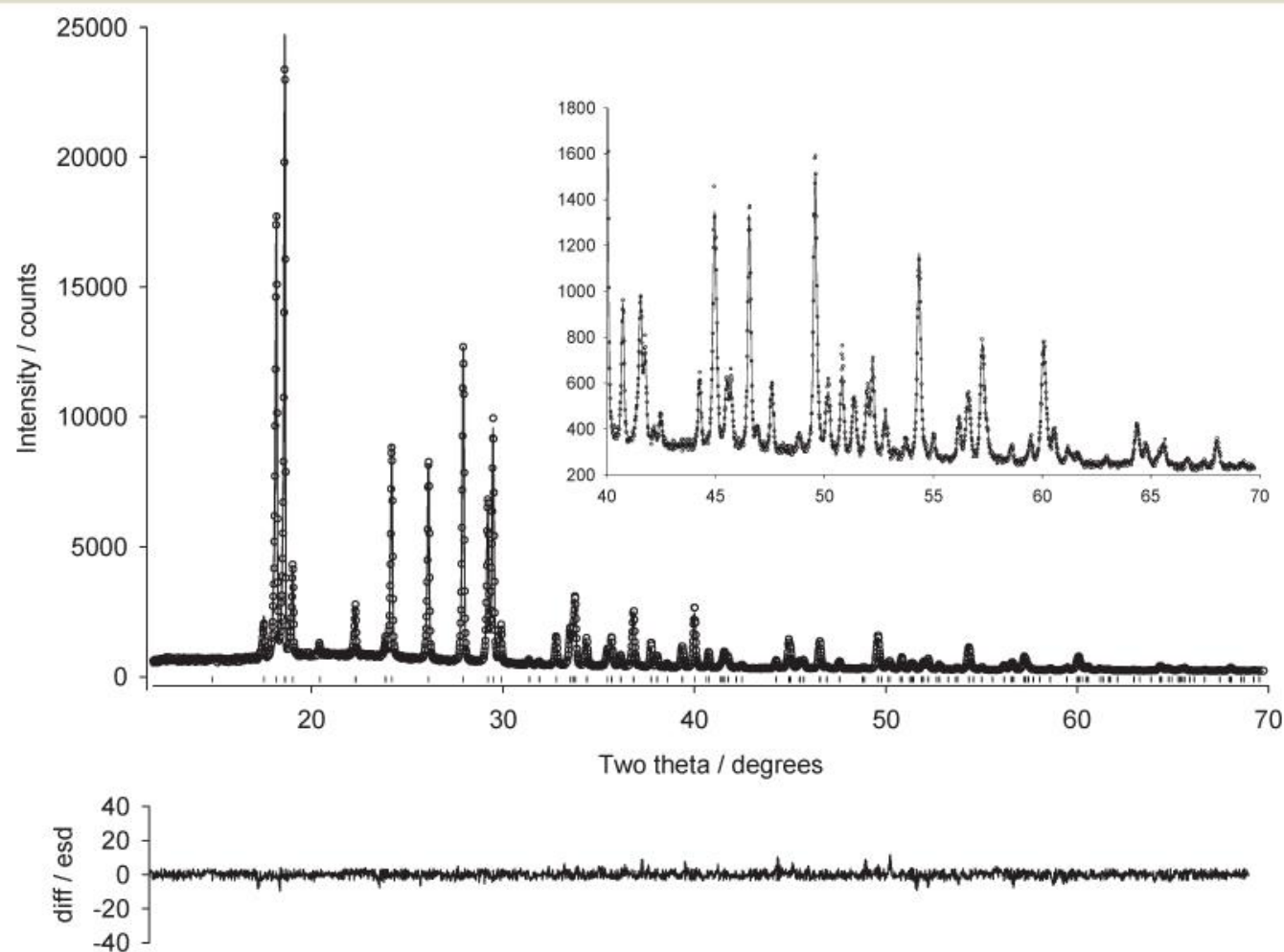

Fig. 2 Final observed (points) and calculated (line) and difference $\left[\left(\mathrm{y}_{\mathrm{obs}}-\mathrm{y}_{\mathrm{cad}}\right) / \sigma\left(\mathrm{y}_{\mathrm{css}}\right)\right]$ profiles for the restrained Rietveld refinement of CTNI.

The sorption-desorption isotherm for CTN I shows more complex behaviour. The sample shows no significant mass change until $60 \%$ R.H. Between 60 to $80 \%$ R.H. the sample increases in mass by $14 \%$ as a result of the transformation to the monohydrate. During desorption, at R.H. $<20 \%$ the water molecules in the monohydrate structure are released during the transformation to anhydrous CTN II. The $2^{\text {nd }}$ DVS cycle follows the similar trend as observed with phase changes between CTN monohydrate and CTN II. This transformation of CTN II (obtained by in situ desolvation) to CTN monohydrate occurs at $40 \%$ R.H., ca. $10 \%$ R.H. higher than the original CTN II sample (obtained by solution recrystallisation). These differences in 

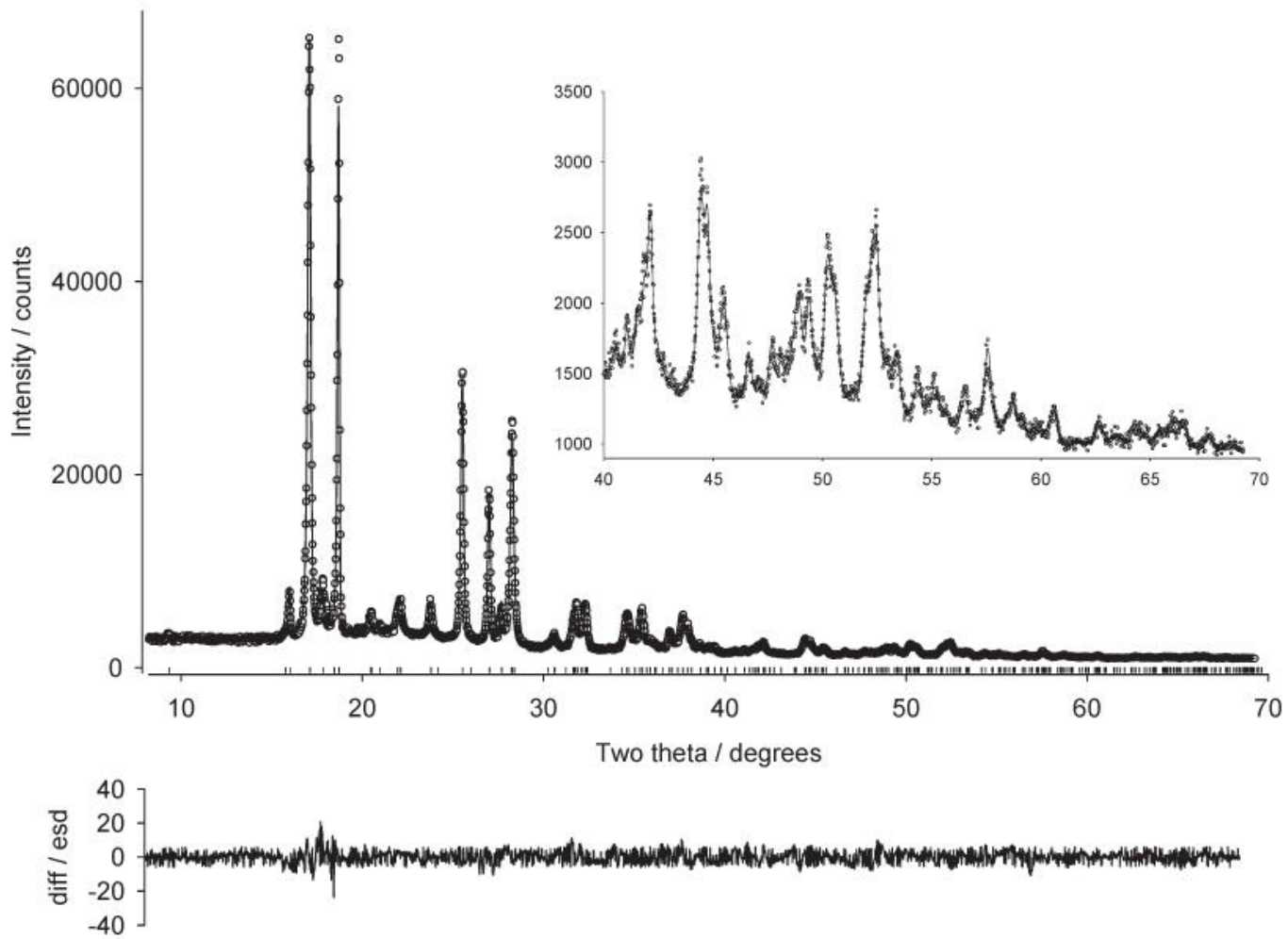

Fig. 3 Final observed (points) and calculated (line) and difference $\left[\left(y_{o b s}-y_{c a b}\right) / \sigma\left(y_{d a s}\right)\right]$ profiles for the restrained Rietveld refinement of CTN III.

Table 2 Crystallographic data for CTN I, II and formic acid solvate

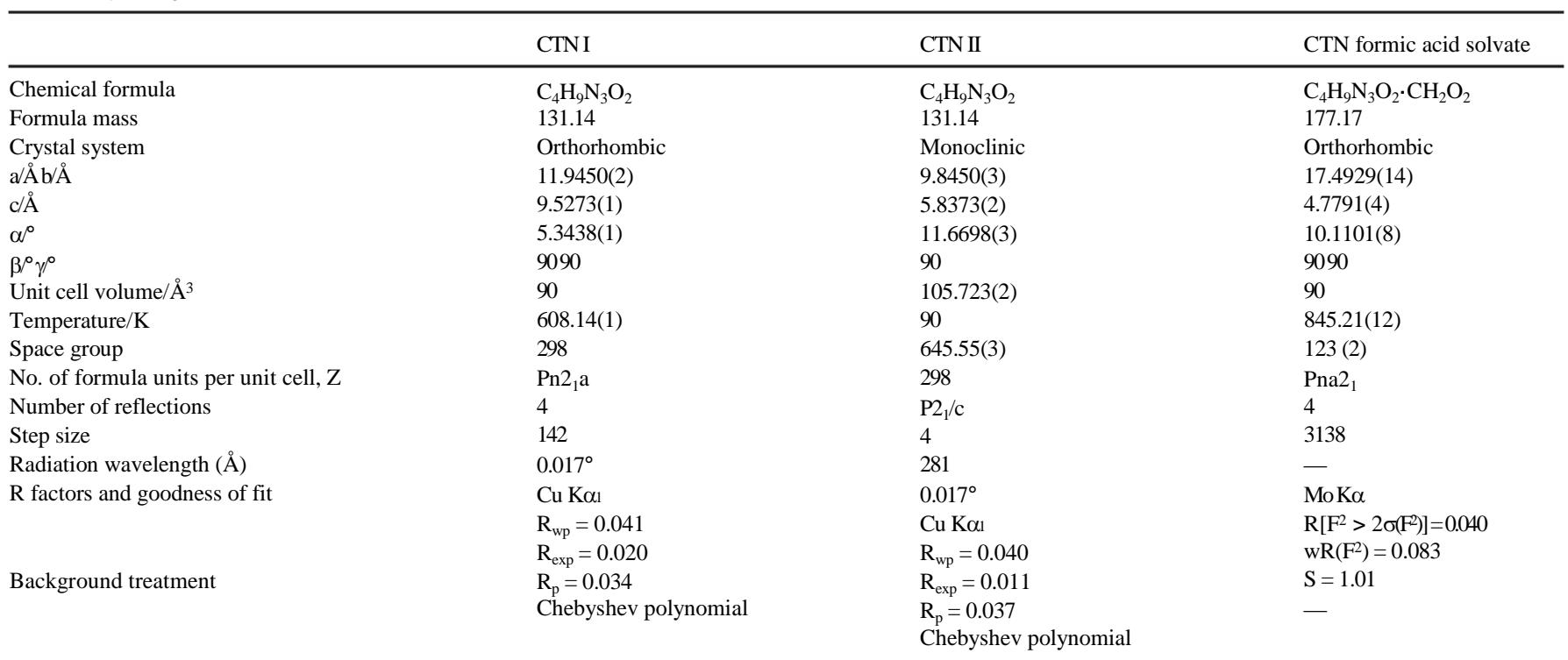

desolvation kinetics can be attributed to differences in the particles used in the two experiments.

Crystal structure analysis

The packing arrangements of the CTN molecules in the three novel structures were compared with each other and the previously characterised monohydrate structure using XPac program. XPac identifies common zero, one, two and three-dimensional (0-, 1-, 2- and 3-D) geometric arrangements of molecules termed
Supramolecular Constructs (SCs). ${ }^{31,32}$ A 1-D SC, $\mathrm{A}_{0}$, is found in all four CTN structures and is considered to be the primary SC and all four structures result from different packing arrangements of this construct (Fig. 5). $\mathrm{A}_{0}$ comprises a zig-zag hydrogen bonded chain of CTN molecules composed of $\mathrm{NH} \cdots \mathrm{O}$ hydrogen bonds from each $\mathrm{NH}_{2}$ group of the guanidinium cation to the carboxylate anion $\mathrm{O}$ atoms of the adjacent CTN zwitterion forming an $\mathrm{R}^{2} \frac{\mathrm{T}}{2} \square$ motif. ${ }^{33}$ These hydrogen bonds in each of 

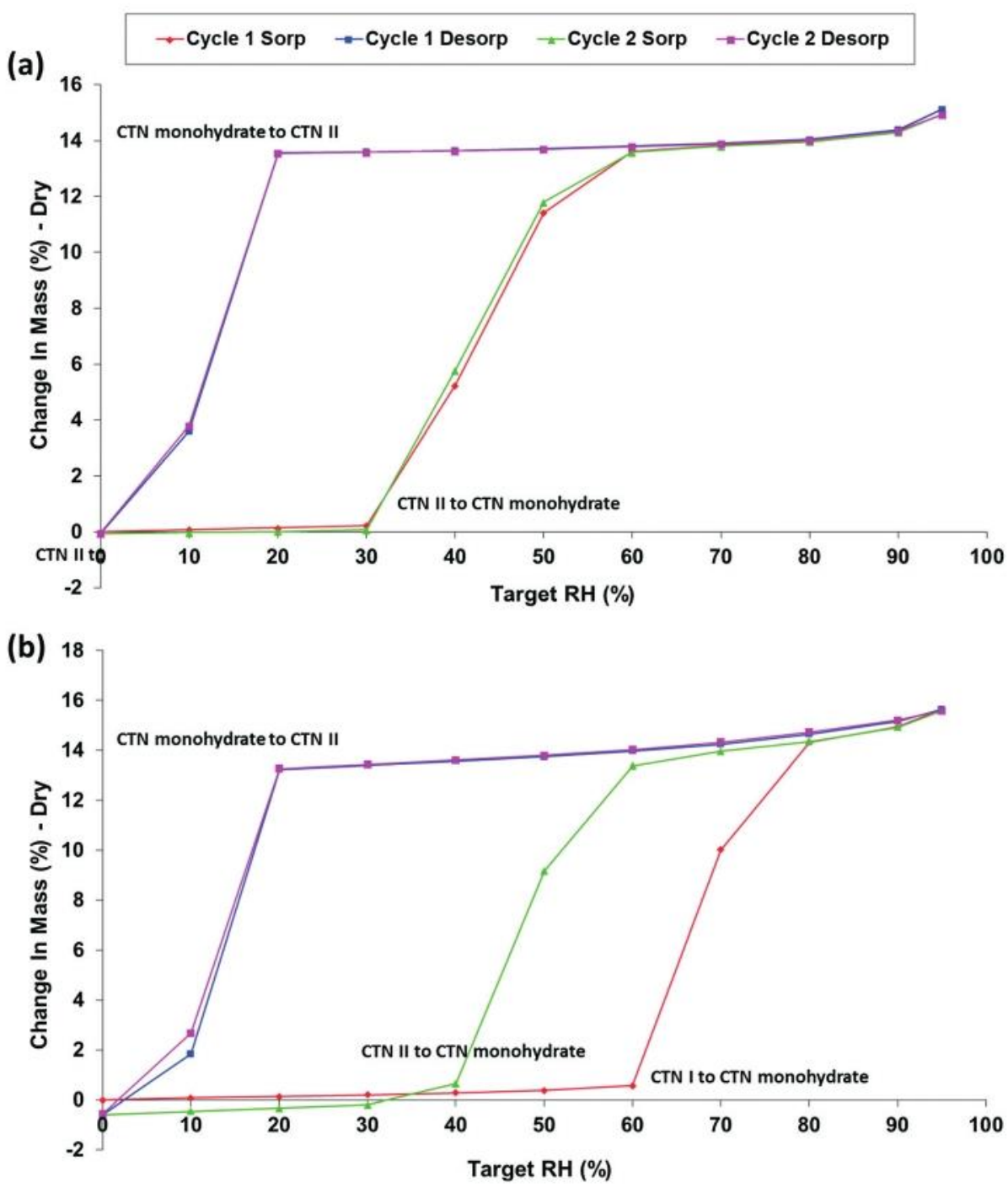

Fig. 4 DVS isotherm plots for CTN anhydrous forms. Various symbols on sorption and desorption curves correspond to data points that fulfils the preset equilibrium condition (mass change $<0.001 \%$ ). Cycles started using the (a) CTN II and (b) CTN I.

the four forms have similar $\mathrm{N}(-\mathrm{H}) \cdots \mathrm{O}$ bond lengths with values in the range 2.775-2.999 $\AA$. The axis of propagation of this hydrogen bonded chain defines the $t_{1}$ translation vector of $\mathrm{A}_{0}$.

CTN formic acid solvate (top left, Fig. 5) is significantly different from CTN I, II and the monohydrate. In this case the $\mathrm{A}_{0}$ chains are linked into a 2-D hydrogen-bonded sheet along the crystallographic b,c-plane by $\mathrm{N}-\mathrm{H} \cdots \mathrm{O}$ hydrogen bonds. These hydrogen bonds are formed between hydrogen atom of $\mathrm{NH}_{2}$ group and one carboxylate $\mathrm{O}$ atom of the CTN molecule adjacent in the b-direction with the second guanidinium $\mathrm{NH}_{2}$ hydrogen forms $\mathrm{H}$-bond with the carbonyl $\mathrm{O}$ atom of a formic acid molecule in the - bdirection. The formic acid molecule in turn forms an $\mathrm{O}-\mathrm{H} \cdots \mathrm{O}$ hydrogen bond to a second creatine molecule. This terminates the intermolecular hydrogen bonding along the a-axis resulting in the structure being composed of repeating hydrogen bonded and nonbonded layers.

CTN I, II and the monohydrate all contain the higherdimensional 2-D SC $\mathrm{A}_{1}$ in which the $\mathrm{A}_{0}$ chains stack along a second axis perpendicular to $t_{1}$, defined as vector $t_{2}$, along the b-axis in CTN II and the monohydrate and along the c-axis in CTN I (Fig. 5). In CTN I, the $A_{1}$ layers stack in parallel along the a-axis with the methyl groups in each $A_{1}$ layer oriented in the $-\mathrm{b}$ direction. In CTN II and the monohydrate, the $\mathrm{A}_{1}$ constructs are stacked along the a-axis and neighbouring layers are related by $2_{1}$ symmetry along the axis. This results in a different arrangement of $A_{1}$ constructs with the methyl groups pointing in the $\mathrm{b}$ and $-\mathrm{b}$ directions in alternate layers.

In CTN II and CTN monohydrate two $\mathrm{A}_{1}$ layers oriented in opposite directions along $\mathrm{b}$, hydrogen bonded to each other through $\mathrm{NH} \cdots \mathrm{O}$ contacts perpendicular to the $t_{1}, t_{2}$ plane (crystallographic a-axis) to form the bilayer $\mathrm{A}_{2}$. In CTN II, the $\mathrm{A}_{2}$ bilayers are directly hydrogen bonded to each other through $\mathrm{NH}$... O contacts while in CTN monohydrate water molecules are positioned between the bilayers forming hydrogen bonds between amine and carboxylate groups on the neighbouring bilayers. This difference in interlayer hydrogen bond connec- tivity changes the relative positions of the bilayers along the 


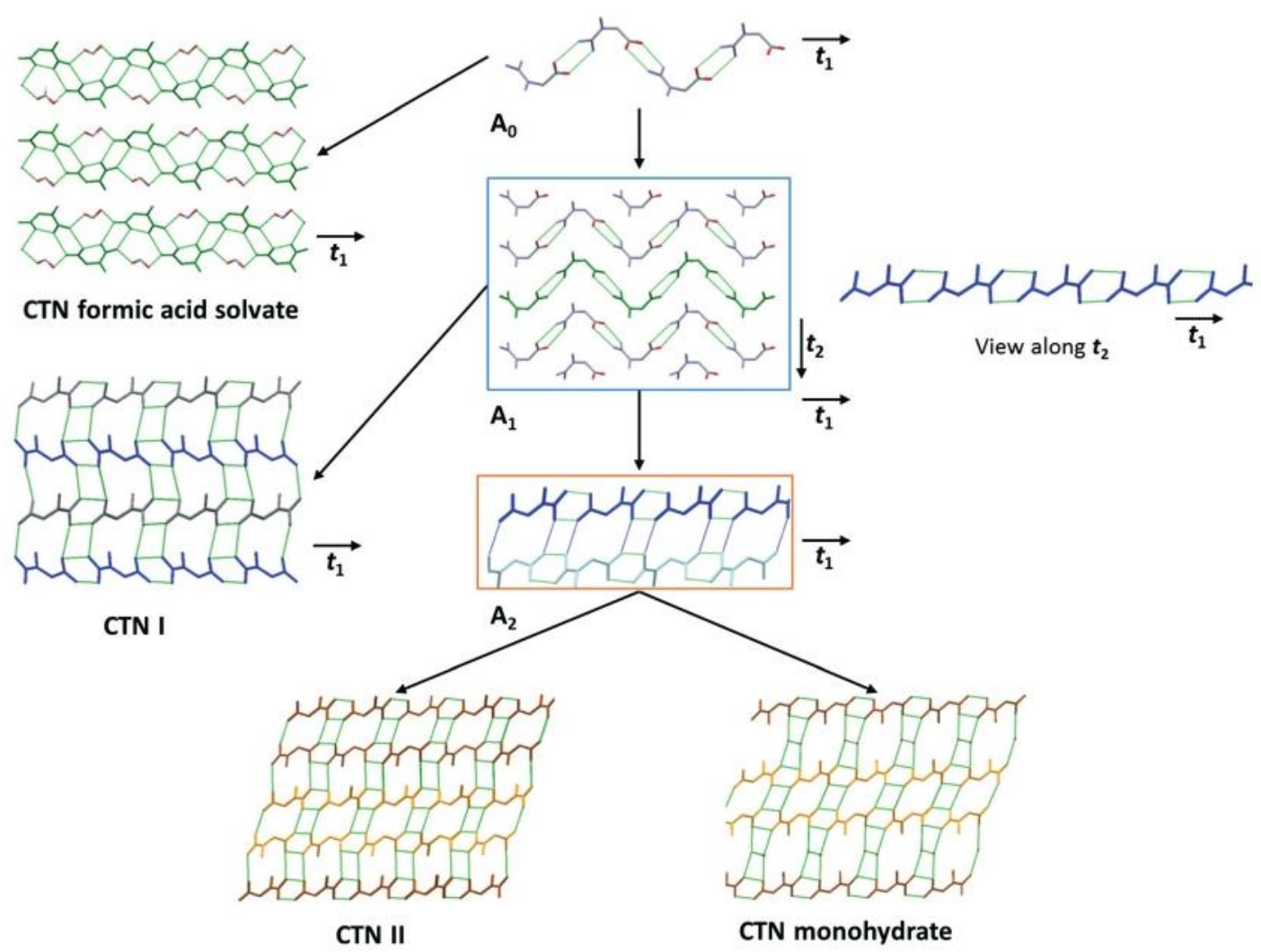

Fig. 5 Diagram illustrating the structural relationships between CTN I, II, CTN monohydrate and CTN formic acid solvate.

a-axis, restricting the crystal packing similarity to 2-D. Data for the base vectors of these constructs are given in ESI† (Table S4).

The crystal structures of CTN II and CTN monohydrate show the greatest similarity amongst all the physical forms of CTN. The two structures differ only by the presence of a layer of water molecules between $\mathrm{A}_{2}$ bilayers in CTN monohydrate. This close structural relationship between the crystal structures provides an explanation for the preferential desolvation of CTN monohydrate to produce CTN II observed from the DVS experiments. When water is removed from CTN monohydrate the structure collapses to CTN II. This facile transformation mechanism also explains why form II transforms to the monohydrate during storage under ambient conditions. Form I is stable under a wider range of $\%$ R.H which may be as a result of the greater structural rearrangement required to transform the $\mathrm{A}_{1}$ to $\mathrm{A}_{2} \mathrm{SCs}$ in CTN I and the monohydrate respectively.

CSP clearly has an increasing role in the investigation of physical form diversity in molecular materials and it is encouraging that a CSP study of CTN ${ }^{9}$ successfully predicted the CTN II structure allowing the crystal structure to be con- firmed by Rietveld refinement against experimental powder data. In contrast, in this work CTN II has been determined and verified from powder data using direct space methods and periodic density functional theory calculations respec- tively. The prediction and experimental structure are in good

agreement with an $\mathrm{RMSD}_{15}$ of $0.117 \AA$.

Whilst CTN II was predicted as the thermodynamically most stable form, CTN I was not found in the search. This is most likely because the study was restricted to only 5 com- monly observed space groups for crystal structures of organic zwitterions and excluded Pn $2_{1}$ a in which CTN I packs.

\section{Conclusions}

A multidisciplinary study of CTN using experimental crystallisation coupled with VT-XRPD has led to the discovery of three polymorphic forms of CTN and a formic acid solvate. Accurate structure determination is vital for better under-standing of the basic science underpinning solid-state diver- sity and SDPD has provided access to accurate structural information for CTN I and II in the absence of suitable single crystals. Further work is ongoing to obtain the structure of CTN III and enable comparison with the known structures and reveal whether it is also based on $\mathrm{SC} \mathrm{A}_{1}$ or on an alternative packing motif.

Understanding the relationship between structure and properties is a key driver for the investigation of the crystal structure of molecular solids. Here the structural relation- ships between CTN I, II and CTN monohydrate has provided insight into the desolvation mechanism of CTN monohydrate and the increased relative stability of CTN I upon exposure to elevated \% R.H. compared with CTN II. This knowledge has important implications for effective physical form purity dur- ing crystallisation, product handling and manufacture and on subsequent storage and the subsequent product perfor- mance of this widely used oral nutritional supplement. 


\section{Acknowledgements}

The authors thank EPSRC for funding this work through the Basic Technology program Control and Prediction of the Organic Solid State (www.cposs.org.uk).

\section{References}

1 T. Wallimann, M. Wyss, D. Brdiczka, K. Nicolay and H. M. Eppenberger, Biochem. J., 1992, 281, 21-40.

2 M. L. Watsford, A Murphy, W. L. Spinks and A. D. Walshe, J. Strength Cond. Res., 2003, 17, 26-33.

3 M. L. Guerrero-Ontiveros and T. Wallimann, Mol. Cell. Biochem., 1998, 184, 427-437.

4 C. S. Frampton, C. C. Wilson, N. Shankland and A. J. Florence, J. Chem. Soc., Faraday Trans., 1997, 93, 1875-1879.

5 Y. Kato, Y. Haimoto and K. Sakurai, Bull. Chem. Soc. Jpn., 1979, 52, 233-234.

6 H. Mendel and D. C. Hodgkin, Acta Crystallogr., 1954, 7, 443-446.

7 Y. Sakata, S. Shiraishi and M. Otsuka, Colloids Surf., B, 2004, 39, 187-193.

8 K. D. Alekha, M. Yoonsun and P. Abira, J. Pharm. Sci., 2002, 91, 708-718.

9 M. D. King, T. N. Blanton, S. T. Misture and T. M. Korter, Cryst. Growth Des., 2011, 11, 5733-5740.

10 J. Aaltonen, M. Alles $\varnothing$, S. Mirza, V. Koradia, K. C. Gordon and J. Rantanen, Eur. J. Pharm. Biopharm., 2009, 71, 23-37.

11 T. Gelbrich and M. B. Hursthouse, CrystEngComm, 2005, 7, 324-336.

12 R. M. Bhardwaj, L. S. Price, S. L. Price, S. M. Reutzel-Edens, G. J. Miller, I. D. H. Oswald, B. F. Johnston and A. J. Florence, Cryst. Growth Des., 2013, 13, 1602-1617.

13 A. J. Florence, A. Johnston, P. Fernandes, N. Shankland and

K. Shankland, J. Appl. Crystallogr., 2006, 39, 922-924.

14 P. O. Bergström, A. Fischer, L. Kloo and T. Sebhatu,

J. Pharm. Sci., 2006, 95, 680-688.

15 M. D. Eddleston, S. Sivachelvam and W. Jones, CrystEngComm, 2013, 15, 175-181.
16 A. J. Florence, B. Baumgartner, C. Weston, N. Shankland, A. R. Kennedy, K. Shankland and W. I. F. David, J. Pharm. Sci., 2003, 92, 1930-1938.

17 K. Shankland, W. I. F. David and D. S. Sivia, J. Mater. Chem., 1997, 7, 569-572.

18 R. J. Hill and I. C. Madsen, Structure Determination from Powder Diffraction Data, ed. W. I. F. David, K. Shankland, L. B. McCusker and C. Baerlocher, Oxford University Press, Oxford, 2002, pp. 114-116.

19 A. Boultif and D. Louer, J. Appl. Crystallogr., 1991, 24, 987-993.

20 G. Pawley, J. Appl. Crystallogr., 1981, 14, 357-361.

21 W. I. F. David, K. Shankland, J. van de Streek, E. Pidcock, W. D. S. Motherwell and J. C. Cole, J. Appl. Crystallogr., 2006, 39, 910-915.

22 S. J. Clark, M. D. Segall, C. J. Pickard, P. J. Hasnip, M. I. J. Probert, K. Refson and M. C. Payne, Z. Kristallogr., 2005, 220, 567-570.

23 R. M. Bhardwaj, B. F. Johnston, I. D. H. Oswald and A. J. Florence, Acta Crystallogr., Sect. C: Cryst. Struct. Commun., 2013, 69, 1273-1278.

24 A. J. Florence, J. Bardin, B. Johnston, N. Shankland, T. A. N. Griffin and K. Shankland, Z. Kristallogr., 2009, 215-220.

25 H. Rietveld, J. Appl. Crystallogr., 1969, 2, 65-71.

26 A. A. Coelho, TOPAS ACADEMIC User Manual Version 4.1., Bruker AXS GmbH, Karlsruhe, Germany, 2007.

27 A. J. Florence, C. T. Bedford, F. P. A. Fabbiani, K. Shankland, T. Gelbrich, M. B. Hursthouse, N. Shankland, A. Johnston and P. Fernandes, CrystEngComm, 2008, 10, 811-813.

28 Bruker, APEX2, SAINT and SADABS, Bruker AXS Inc., Madison, Wisconsin, USA, 2007.

29 G. Sheldrick, Acta Crystallogr., Sect. A: Found. Crystallogr., 2008, 64, 112-122.

30 L. Farrugia, J. Appl. Crystallogr., 2012, 45, 849-854.

31 T. Gelbrich and M. B. Hursthouse, CrystEngComm, 2006, 8, 448-460.

32 SC-supramolecular construct can be defined as a recurring periodic or discrete arrangement of molecules with unique spatial characteristics. SCs are assigned irrespective of the intermolecular contact patterns of the interactions stabilising the assemblies.

33 M. C. Etter, Acc. Chem. Res., 1990, 23, 120-126. 